\title{
Oralidade e escrita na cultura popular ${ }^{1}$ : os calendarios impresos como mediación e transición cara a cultura escrita e urbana
}

\author{
Oral tradition and writing in popular culture: printed calendars, a \\ transition towards written culture in urban society
}

\author{
Alicia DÍAZ BALADO \\ Universidade de Santiago de Compostela
}

\begin{abstract}
RESUMO: O avance na consolidación do modelo económico capitalista esixía racionalizar a medida do tempo nos diferentes territorios europeos, tanto para o fomento da productividade económica, como para o 'disciplinamento' social. Así, o calendario, que fora unha mediación característica, pero tamén variable, da sociedade tradicional, foise convertendo durante a Modernidade tardía e a Contemporaneidade nunha publicación impresa crecentemente popular, paulatinamente normalizada como xénero impreso. Como obxecto de consumo cultural, o calendario ou almanaque incorporou novidades científicas nas súas páxinas publicitarias, conxuntamente cos contidos máis tradicionais e desenvolveu un rol formativo en contextos informais de educación.
\end{abstract}

PALABRAS CHAVE: Calendario. Tradición oral. Impresos. Modernidade. Consumo cultural. Educación informal.

ABSTRACT: The consolidation of capitalism made it necessary to rationalize the measurement of time in different areas of Europe for two reasons - to foster economic productivity and to achieve social discipline. Thus the calendar, which had been a typical, but variable measurement, gradually became an increasingly popular printed publication in late modernity and contemporary times. As an object of cultural consumption, the calendar or almanac started to include scientific innovations in the form of advertisements, in addition to its traditional contents. The calendar also played an important role in informal educational settings.

KEY WORDS: Calendar. Oral tradition. Printed materials. Modernity. Cultural consumption. Bourgeois society. Cultural reproduction Informal Education

\footnotetext{
${ }^{1}$ Alén das posibles controversias suscitadas polo construto 'cultura popular', considera Narciso de Gabriel que tal concepto "sigue siendo valioso e ilumina dimensiones y aspectos de la realidad que de otra forma quedarían oscurecidos". Vid. Narciso de Gabriel, "Clases populares y culturas escolares", en La escuela y sus escenarios. Actas de los IX Encuentros de Primavera en El Puerto, eds. Juan Gómez Fernández et al. (El Puerto de Santa María: Ayuntamiento, 2007), 243-268.
} 


\section{Tempo e calendarios: entre a tradición e os usos novos da Modernidade ${ }^{2}$}

A sociedade tradicional posuía os seus propios modos de medir o paso do tempo, vencellado á simplicidade tecnolóxica, que se concretaba no emprego de calendarios fortemente pautados polos tempos liturxicos cristianos, trasunto eles mesmos de clasificacións previas alicerzadas no mundo romano, ou mesmo á súa ausencia, porque, con anterioridade á aparición do reloxio, para a maioría da poboación a estimación do tempo vinculábase ao espazo; do que resultaba, obviamente, unha estimación imprecisa e variable, como sinalou Elias ${ }^{3}$ :

Entre as antigas medidas do tempo atópanse os movementos do sol, a lúa e as estrelas, de cuxas relacións e regularidades temos hoxe en día unha idea moi clara da que os nosos antepasados careceron. Se nos remontamos a un pasado bastante remoto, veremos que hai estadios onde os homes non teñen aínda a capacidade de relacionar os múltiples e complexos movementos dos astros para facerse un esquema relativamente ben integrado.

Este modo tradicional viuse alterado paulatinamente polos modos de vida e organización social xurdidos en Europa arredor do século XVII, cuxa in uencia posterior os convertiu en usos mundiais, da man por outra parte dos avances técnicos referidos á construción e precisión de reloxios e ao establecemento de reguladores temporais, o que fixo posible a experiencia do tempo como un uxo uniforme. É o que chamamos a Modernidade, á que entre tantos outros autores se refireu Giddens ${ }^{4}$ A Modernidade introduciu formas de vida que modificaron a orde social tradicional e entre os elementos que contribuiron á tal modificación, sitúase a medición do tempo.

Sen embargo, isto non significou que os modos tradicionais de medición non prolongasen a súa pervivencia e utilidade, coa conseguinte continuidade na utilización dos calendarios como instrumentos chegados da sociedade tradicional. Neste punto circunscríbese a importancia dos calendarios.

Cómpre poñer de relevo que non todo foi un problema técnico, pois as mudanzas técnicas quedan impotentes para explicar por si soas o paso do tempo medieval ao tempo moderno, xa que se pasa dunha división eclesiástica a unha división laica, centrada arredor das horas de traballo da incipiente sociedade burguesa, ao que aludiu Le Goff ${ }^{5}$ e como tamén o indica Betts ${ }^{6}$ : presumiuse tácitamente que a procura dunha maior precisión fora a impulsora das melloras técnicas nos reloxios, pero é ben máis probable que a forza motriz radicase na necesidade social, tal e como revela a forma na que evolucionaron os reloxios. O tempo comezou a representar un elemento susceptible de transformarse en

\footnotetext{
${ }^{2}$ Co meu agradecemento ao profesor Antón Costa Rico, con quen puiden contrastar aspectos, formulacións e referencias aquí examinadas e expostas.

${ }^{3}$ Norbert Elias, Sobre el tiempo (Madrid: Fondo de Cultura Económica, 1989), 50-51.

${ }^{4}$ Anthony Giddens, Consecuencias de la modernidad (Madrid: Alianza, 1994).

${ }^{5}$ Jacques Le Goff, Tiempo, trabajo y cultura en el Occidente medieval (Madrid: Taurus, 1983).

6 Jonathan Betts, "Desarrollo de modernos sistemas de medición del tiempo", en El tiempo a través del tiempo, ed. Kristen Lippincott (Barcelona: Grijalbo, 2000), 134-167.
} 
beneficio económico, polas gañancias derivadas da productividade. E aquí xogou un seu papel a presenza social de calendarios impresos, como unha mediación complementaria na ordenación do tempo social.

Neste senso, Le Goff e outros historiadores afirman que co incremento das redes comerciais e das actividades artesás o tempo comezaría a aceptarse como algo medible ${ }^{7}$, susceptible de selo en cuestións tan fundamentais como os tempos de traballo de obreiros e artesáns. Atrás quedaba entón un tempo no que os negocios do mercader e do campesiño quedaban nas mans de Deus a través da orde temporal da natureza proclive a ofrecer períodos de escasez e abundancia. Nas cidades mercantís, a medición temporal a través das horas do reloxio, nunhas horas que todos puidesen verificar do mesmo modo, foi unha necesidade para cuestións máis complexas que os tempos de traballo anteriormente citados. Banqueiros, cambistas, contables e notarios precisaban dun tempo unificado para as transaccións monetarias e para fixar o valor das letras de cambio ou dos seguros de mercancías e paulatinamente, o traballo nas cidades deixou de medirse en función das horas do día ou do tempo do sol, para rexirse, entón, mediante as horas artificialmente iguais do reloxio. Porén, aquí tamén xogou un seu papel a presenza social de calendarios impresos -nos que aquí nos centraremos-, como unha mediación complementaria na ordenación do tempo social.

\section{Os calendarios como impresos e como indicios de consumo cultural}

No contexto da sociedade tradicional os almanaques e calendarios, que se viñan publicando desde o s. XVI e mantivéronse coas súas adaptacións mesmo ata a actualidade, mantendo unha considerable funcionalidade, entre outros motivos porque mediante os seus contidos procuraban ofrecer unha imaxe comprensible do mundo, tal como derá a entender a fins do século XVI o cosmógrafo de Filipe II, Rodrigo Zamorano, na súa Cronología y repertorio de la razón de los tiempos.

A sona conseguida polos calendarios e almanaques -fenómeno característico dunha época- atópase, ademais, altamente relacionada coas novidade dos productos difundidos pola imprenta. Deste xeito, Mínguez ${ }^{8}$ expon que os almanaques chegan a converterse, en particular durante a segunda metade do século XIX por mor da maior alfabetización á que os mesmos almanaques puideron servir de soporte, en publicacións con categoría de 'verdadeiros' libros, que conteñen entre as súas páxinas, xunto á cronoloxía do ano en curso e aos pronósticos naturais e efectos da lúa, relatos, datos históricos, coñecementos de saúde, de agricultura e de gandaría, guías de transporte ou partituras musicais. Almanaques, prognósticos ou diarios serán publicacións destinadas á medición do tempo e á inclusión de previsións sobre o mesmo. Falamos de impresos considerados menores, xeralmente obviados polos historiadores, ata momentos moi recentes nos que a corrente da historia cultural os resgatou, pese á súa popularidade. Estes impresos compartirían

\footnotetext{
${ }^{7}$ Pietro Redondi, Historias del tiempo (Madrid: Gredos).

8 José Luis Mínguez, Os calendarios Galegos do século XIX: historia e catálogo do calendario xeral de Galicia (Santiago de Compostela: Xunta de Galicia, 2004), 18.
} 


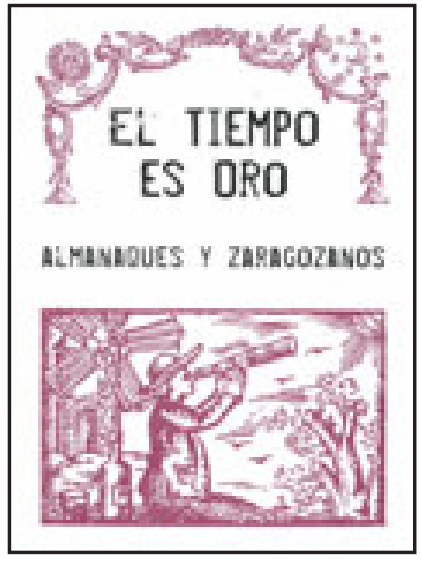

as características xerais da súa periodicidade e un acervo de contidos como a táboa cronolóxica, o calendario, o santoral ou os datos astronómicos, como as fases lunares e outras cuestións variadas como certas indicacións civís, consellos ou poesías.

Un dos rasgos centrais dos calendarios impresos será o seu carácter divulgativo en torno a diversos coñecementos que trascenden 0 saber astronómico. 0 ton divulgativo do que se fai mención foi aparellado ao nacemento e á evolución dos calendarios desde as súas orixes ata a súa significación actual, na pervivencia dalgúns dos seus títulos máis senlleiros. Os almanaques, xunto con outras publicacións de parecida orde, participan, en varias das súas acepcións, da cualidade de popularidade que menciona Hall ${ }^{9}$, no sentido dunha popularidade que se asocia aos productos escoitados, comprados ou consumidos polas masas; vinculados ao reducto dos sectores populares ao longo do tempo; ou das accións que realiza o pobo; así como das formas e actividades enraizadas nas condicións sociais e materiais, que quedan incorporadas ás tradicións e prácticas denominadas populares.

As chamadas publicacións menores foron, así, artigos obxecto de significativa divulgación, antano vendidos masivamente, por formar parte dos usos dun amplo conxunto de poboación na sociedade tradicional. Con todo, o seu carácter popular non impediu que compartisen uns determinados diálogos e interrelacións coa cultura oficial, desde 0 momento no que, tanto o calendario xeral nacido como publicación e impulsado desde 0 poder público canda o século XVIII, como o almanaque, estiveron sometidos ao privilexio de impresión que concedía a autoridade, ao tempo que a súa orixe e desenvolvemento correron parellas -como se sinalou- ao desenvolvemento e difusión da imprenta. Fragmentos de cultura popular, integrados na oficialidade da cultura refrendada pola autoridade pública.

A este propósito, Mari ${ }^{10}$ faise eco da re exión aportada por Habermas, quen salientou como os pensadores da Modernidade non foron quen de comprender as preguntas da cultura popular, calificada xeralmente a través de sinónimos como "salvaxe" ou "bárbara", asumindo con impostación unha fractura entre a cultura oficial e a popular que tería desprazado a ésta última aos ámbitos do folcklórico ou marxinal. Existe, realmente, esta fractura? Probablemente, de modo parcial.

Se entendemos os almanaques ou calendarios como a mostra dun producto cultural marcadamente popular, que cumpriu cunha clara función divulgativa, entón adquiren sentido as palabras de Bourdieu ${ }^{11}$ acerca do consumo cultural. $O$ autor francés relaciona as

\footnotetext{
${ }^{9}$ Víctor Manuel Marí, "Movimientos sociales y educación popular en tiempos de globalización", Revista de Educación. Monográfico de Educación no formal, Septiembre-Diciembre, n 338, (2005): 177-192.

${ }^{10}$ Víctor Manuel Marí, "Movimientos sociales y educación popular en tiempos de globalización", 177-192.

${ }_{11}$ Pierre Bourdieu, El sentido social del gusto. Elementos para una sociología de la cultura (Madrid: Siglo XXI, 2010).
} 
necesidades culturais cos productos da educación. As prácticas culturais, como a asistencia a museos ou concertos ou as preferencias en materia de literatura ou música estarían ligadas estreitamente, en primeiro lugar, ao nivel de instrucción e seguidamente á orixe social. A xerarquía socialmente recoñecida das artes correspóndese coa xerarquía social dos consumidores; de xeito que os gustos funcionarían como marcadores privilexiados de clase. Por engadido, o consumo, en tanto que proceso de comunicación, implica un acto de decodificación ou desciframento, que supon o dominio dun código que se debe posuír para que o obxecto ou a obra de arte adquiran sentido e interese para o decodificador.

Os calendarios ou almanaques, entendidos como obxectos de consumo cunha intención divulgativa, constitúen, pois, materiais impresos dirixidos a un público determinado que demanda os seus contidos. Estes, relacionados coas actividades económicas primarias, son contidos asociados primordialmente á agricultura con certas concesións tamén á actividade marítima; materiais de estudio que intercalan entre as súas páxinas abondosas mostras de cultura popular.

Con esta cautela diante, entendemos que a presenza social dos calendarios ou almanaques óbriganos a abrir unha liña de análise arredor da práctica cultural da lectura nos entornos populares e da significación que estes textos podían ter no contexto social a que nos referimos. No mesmo lugar, Bourdieu ${ }^{12}$ convén na realización dunha crítica arredor do status social do documento no que adquire sentido o coñecemento do uso social dos textos; pois existe unha forma de lectura do texto que permite coñecer o que o texto quere facer ao lector. O propio texto transmite unha información acerca do seu modo de emprego e tamén mediante cuestións de corte tipográfico que inciden no grao de complexidade para a súa decodificación -como a distribución en párrafos ou a inclusión de aspectos de deseño gráfico, títulos, tipo de letra, utilización de letras capitulares-. A concreción dos aspectos tipográficos na organización da lectura varía en función do nivel de instrucción do público destinatario, do mesmo xeito que variarán os seus contidos, susceptibles de ser transmitidos individualmente ou por medio da lectura colectiva.

O público destinatario debe acreditar no "valor simbólico" que se lle recoñece ao texto, fundamentado a través dun pacto tácito entre os productores do escrito e os lectores. Este acordo estaría canalizado mediante a elaboración da crenza sobre o valor do producto intelectual:

(...) Polo tanto, entre as condicións que deben conseguirse para que un producto intelectual sexa producido, está a produción da crenza no valor do producto. ( ...). Dito doutro xeito, o que caracteriza ao ben cultural é que é un producto como calquera outro, co agregado dunha crenza que debe ser producida en si mesma ${ }^{13}$.

Os lectores participan desa crenza e compártena; os destinatarios dos contidos dos calendarios ou almanaques participan do valor de utilidade que os textos aportan, porque engaden un coñecemento de proveito para a súa vida diaria, relacionado, por exemplo,

\footnotetext{
${ }^{12}$ Ibid., 261.

${ }^{13} \mathrm{lbid}$., 261.
} 
coa sucesión de lúas e mareas ou coas feiras da contorna. Os calendarios e almanaques, entón, actuarían como depósitos ou reservas de coñecemento: as súas letras conteñen información de valía para todo o ano, á cal é posible acceder en calquera momento.

Carreño $0^{14}$, en relación cos usos do calendario, indica que co tempo a información proporcionada nos mesmos ampliouse desde as festas relixiosas e os datos astronómicos cara unha temática máis xeral sobre coidados agrícolas, medicina, hixiene ou moral. $\mathrm{A}$ autora recolle como referencia o Almanaque popular y religioso de España para el año $1849^{15}$, onde se fai, para mellorar a lectura, fincapé na vontade de achegamento ás clases subalternas dunha cultura pasada polo tamiz das propias circunstancias ou intereses do autor ou autores, actuantes neste caso como a voz do poder. No propio Almanaque afírmase, segundo recolle Carreño ${ }^{16}$ que poden "chegar a ser poderosos instrumentos da reforma moral e da civilización, propagando útiles verdades ...". En tal sentido, débese sinalar que a preponderancia de calendarios e almanaques radica, segundo as palabras contidas nas súas páxinas, na difusión do amor á virtude que irradia estabilidade para os estados e felicidade pública e particular; 0 que se traduce en equilibrio e benestar para as esferas pública e privada. No prólogo, esta afirmación xira arredor de tópicos como a prosperidade e o apego á relixión, á orde, ao traballo, ao respecto, así como ás institucións protectoras da familia e a propiedade. Toda unha declaración de principios coa que 0 redactor ou redactores pretenden erradicar a alteración e o desvarío sociais a través da defensa da tradición.

A novidade da impresión editorial recolle e reproduce a información propia da cultura tradicional, pero, como obxecto de consumo cultural, incorpora novidades arredor da publicidade, relacionadas coa modernización social. Ao caso, Bonilla ${ }^{17}$ da conta da importancia que o xornalista latinoamericano Manuel Caballero (1849-1926), redactor de almanaques en temas tan diversos como a historia, a política, a literatura ou a economía, lle deu á publicidade nas súas publicacións. En palabras da autora ${ }^{18}$,

Nestes Almanaques uniu información, imaxes e publicidade; ao facelo, vencellou coñecemento, progreso e desenvolvemento do país que se podía palpar na publicidade, pois ela da testemuña da prosperidade do momento e tamén foi complementaria ao discurso da información xeral. Ademais, facía estes calendarios co obxectivo de ensinar as bondades do país e convidar á inversión nos sectores productivos aos empresarios. (p.5).

\footnotetext{
${ }^{14}$ Miryam Carreño, "Almanaques y calendarios en la Historia de la Educación Popular: un estudio sobre España", Revista de Educación, ㄲo 296, (1991):195-216.

${ }^{15}$ Almanaque popular y religioso de España para el año 1849 (Madrid: Imprenta de Don Anselmo Santa Coloma, 1849).

${ }^{16}$ Miryam Carreño, "Almanaques y calendarios...", 199.

${ }^{17}$ Laura Edith Bonilla, "México ilustrado en Almanaques: Manuel Caballero", Historiadoresdelaprensa.com.mx , 2012):1-23. En http://docsse.com/view.php?id=437803 (Date added 3 de feb. de 2012).

18 Ibid., 5.
} 
$\mathrm{E}$, en efecto, en números consultados de $\mathrm{O}$ Gaiteiro de Lugo $^{19}$ obsérvase que, no termo de poucos anos, o espazo e tratamento asignados á publicidade amplíase e pasa a ser obxecto dunha maior atención. Os anuncios insertados, frecuentemente publicitan productos destinados ao traballo agrícola; non é estraño que sexan estes os elementos que no almanaque informan sobre as transformacións traídas polo paso dos anos, ante a case inalterabilidade dos seus contidos. O número para 1927 ofrece, na contraportada, un anuncio da luguesa Óptica Lázaro; en 1929, no mesmo espazo publicítase a máquina de fabricación alemá para picar toxo Badenia, á venda na casa de Ricardo Steudel da Avenida de Moret. Nun cadro similar, os números para 1937 e 1939 anunciaban o papel de fumar Bambú, acompañado xa dun debuxo. Na consulta do número de 1949, obsérvase un maior coidado no tratamento da publicidade, así como a reserva dun maior número de páxinas para a mesma; froito dun estratexia propagandística máis dinámica. En todas as páxinas publicítanse os Polvos Pinós para o engorde de vacas e porcos; catro das páxinas centrais do calendario dedícanse a anuncios continuados e na contraportada insértase un anuncio completo da citada marca.

O interese dos contidos proporcionados pola publicidade non é desdeñable, pois a través destes aprécianse os tímidos inicios do que representaría a posterior implantación do mercado de consumo cunha certa modificación de técnicas, hábitos e modos de vida.

\section{Permanencia e pervivencia nas sociedades tradicionais. Oralidade e escrita.}

Na nova sociedade que comeza a adoptar as formas da modernidade, a escritura posúe un innegable potencial expansivo, transmisor de pautas, normas e valores. Co almanaque, o texto escrito difunde para un público diverso un conxunto ampliado de coñecementos convenientes para a súa existencia social. Asistimos a un momento no que parte do coñecemento que fora transmitido oralmente adopta unha nova forma de expansión mediante as páxinas escritas.

En re exións bens interesantes polo seu ton interpretativo Fermín Bouza ${ }^{20}$ refírese á estendida pero errónea opinión de que o paso da Idade Media cara á Época moderna equivaleu ao paso da lectura de textos escritos desde a anterior transmisión oral de coñecementos. Sen embargo, para o autor, a situación tería sido máis complexa. Na Baixa Idade Moderna, na transmisión das ideas actuaban tres formas posibles de comunicación: oral, icónico-visual e escrita, axeitadamente desenvolvidas e posuídoras dos seus sistemas de ensinanza e comprensión. Así,

\footnotetext{
${ }^{19}$ O Gaiteiro de Lugo. (Lugo: Imprenta de Xerardo Castro, 1927, 1928, 1929, 1937, 1939, 1949, 1973).

${ }^{20}$ Fermín Bouza, Del escribano a la biblioteca. La civilización escrita europea en la Alta Edad Moderna. (Siglos XV-XVII) (Madrid: Síntesis, 1992), 24.
} 
(...) durante os séculos XV, XVI e XVII non estiveron en retroceso, senón en pleno auxe, as formas de expresión oral e icónico-visual e, o que é máis, que éstas non se circunscribiron aos límites da esfera popular dos iletrados, nin tampouco ao espazo xeográfico marcado polas novas fronteiras que vira elevarse o proceso de confesionalización. No que se refire ás formas de comunicación, en modo algún se pode dividir o continente en dúas Europas, unha primeira racionalmente moderna, precapitalista e escritófila, e unha segunda feudal e católica, anclada no escurantismo da verbofilia e no sentimentalismo da visualización barroca. ${ }^{21}$

Para o mesmo autor ${ }^{22}$ constitúe un erro tradicionalmente aceptado o establecemento dunha equivalencia entre a cultura das élites e a cultura dos estamentos nobiliario e relixioso, así como a consideración de que a cultura popular sería a propia dos non privilexiados socialmente. Como precisa o autor, a realidade máis ben respostaba á presenza dun nutrido conxunto de nobres e clérigos analfabetos á marxe da minoría letrada, á que tamén se sumaban un conxunto de sectores populares. Parece ser certo que a grandes rasgos, a relación entre formas culturais e formas de comunicación na Alta Idade Moderna europea respostaría á seguinte asociación: a cultura popular vincúlase ás formas de comunicación oral e icónico-visual, referida ao contido da tradición; mentres que a cultura de élites relaciónase coas formas de comunicación oral, icónico-visual e escrita, correspondente á gran tradición clásica e cristiá.

Pero, a pesar do reparto heteroxéneo ao que respostaba a comunicación e as súas formas no tempo referido, pode ser constatada a función mediadora da cultura dominante sobre a dominada, que ten o seu espello na expresión escrita, factor que mediatizou a forma na que esta chegou ata os nosos días. Este proceso, estudado por Dubert ${ }^{23}$ no amplo espazo xeográfico- histórico entre a Galicia de finais do século XV e principios do século XX, repítese noutras sociedades europeas da época Moderna. Deste modo, as fontes xudiciais e eclesiásticas consultadas que recolleron as verbas labregas foron, neste caso, os intermediarios de referencia pertencentes á cultura dominante, dos que Dubert ${ }^{24}$ indica a súa praxe, relacionada coa transcripción da fala popular nas testemuñas requeridas desde os estamentos da autoridade:

(...) as claves que formaban parte da memoria individual e colectiva dos grupos subalternos, que aquí se expresaban oralmente e en galego, serían conformadas na práctica polas estructuras narrativas ás que o crego, o escribán ou o oficial de pluma, acudían para dar conta por escrito e en castelán da realidade vivida. ${ }^{25}$.

De tal forma, non só queda modificada a lingua de transmisión, senón tamén o rexistro lingüístico orixinal. A transmisión fidedigna da oralidade propia das clases populares

\footnotetext{
${ }^{21}$ Ibid., 24.

${ }^{22}$ Fermín Bouza, Corremanuscrito. Una historia cultural del Siglo de Oro (Madrid: Marcial Pons, 2001).

${ }^{23}$ Isidro Dubert, Cultura popular e imaxinario social en Galicia, 1480-1900 (Santiago de Compostela: Servicio de Publicacións e Intercambio Científico da USC, 2007), 27.

${ }^{24}$ Ibid., 27.

${ }^{25}$ Ibid., 27
} 
levouse a cabo coa conseguinte perda de información polo camiño. Ao fío, Dubert estuda o mecanismo de dobre negación realizado polas élites letradas galegas. Este residiu na utilización do castelán na transcripción das testemuñas rexistradas, así coma no empeño por transformar en hexemónico o seu proxecto cultural, vencellado á idea da sociedade cristiá e que propiciou a xeración de pautas de conduta específicas en distintas ordes. Tendeuse, polo tanto, á negación da realidade lingüística que sustentaba a cultura popular.

Este feito non foi óbice para que noutros contextos, a minoría letrada utilizase os argumentos da tradición culta ou popular, en función das súas necesidades. No contexto literario, Grignon e Passeron ${ }^{26}$ sinalan a ambigüidade experimentada polos novelistas que seleccionaron os seus heroes entre as clases populares, ante as interrogantes suscitadas polo xeito de trasvasar a fala popular á lingua literaria; no momento no que uns contidos que no pasado foran propios da comunicación oral, comezan a compartir tamén a forma comunicativa da escrita.

Por engadido, os libros e outros materiais impresos tamén terían trascendido os valos do carácter culto, para achegarse aos ouvidos da masa popular, a través da lectura en voz alta, que situou parte da cultura de élites a disposición da maioría non letrada. Neste sentido, Watt citada por Bourdieu ${ }^{27}$ fala do abaratamento dos custes de producción dos libros nos séculos XVI de XVII, que revela en parte a viabilidade coa que se traspasaron as barreiras entre ambas tradicións. No almanaque, o texto escrito difundiu, para un público amplo, un conxunto amplíado de coñecementos necesarios para a dinámica social, susceptibles de pertencer á realidade lingüística e social da cultura popular mencionada anteriormente. En publicacións como os almanaques, uns contidos que terían sido propios da forma de comunicación oral, comezan a compartir tamén a forma comunicativa da escrita.

O constatable arraigamento do almanaque na sociedade da que forma parte -o hábito da súa compra pasaría de pais a fillos- vencellado á utilidade da información que se achegou aos grupos de destino terían condicionado favorablemente a súa supervivencia: esta continuidade contaría coa in uencia de ambos factores anteriormente sinalados. Polo tanto, o paso cara a modernidade mantivo vixente o almanaque, como publicación centrada e dirixida fundamentalmente ao mundo labrego, coas adaptacións pertinentes dos seus contidos aos tempos recentes. De modo que podemos e debemos anotar a existencia dunha transición cultural, con ecos que aluden á historia da educación vivida entre nós.

Así, pois, a cultura da tradición oral seguiu a ser obxecto central de transmisión mediante almanaques e calendarios impresos, podendo dar lexitimidade a unha parte,

\footnotetext{
${ }^{26}$ Como un valor engadido, pola contra, os autores (1992) suliñan que os escritores se atopan nunha boa situación se son quen de recoller "a súa parte de plusvalía simbólica producida pola importación á esfera culta de materias primas arrancadas ás culturas dominadas (...)". Claude Grignon; Jean-Claude Passeron, Lo culto y lo popular: miserabilismo y populismo en sociología y literatura (Madrid: Ediciones de la Piqueta, 1992), 260. ${ }_{27}$ Pierre Bourdieu, El sentido social del gusto. Elementos para una sociología de la cultura (Buenos Aires: Siglo XXI, 2010), 87-88.
} 
cando menos, das palabras herdadas En palabras de García Carrasco ${ }^{28}$, coa escritura "a comunicación maximiza o seu carácter público máis alá dos límites que permite a cultura fundamentalmente medida pola conversación". O mesmo autor citando a Goody 29 refírese á función da xestión social da escritura no contexto urbano, fronte á cultura oral da aldea ou da comunidade pequena. Entende que a cidade, respecto á aldea, que está asentada na cultura da oralidade,

(...) non é meramente un espacio estructurado de produción; precisamente é a escritura a que institúe a posibilidade de mantemento e preparación desta estructura complexa, reconstruíndo a tradición en forma de leis ou institucións e facendo da constancia escrita unha compoñente de xestión social. ${ }^{30}$

A orixe urbana da escritura nas primeiras comunidades sociais estivo de ordinario ligada á propia burocracia e á organización económica ${ }^{31}$. Foi nun proceso posterior cando a escritura pasou a desempeñar as actuais funcións estéticas e tecnolóxicas de transmisión do saber, así coma tamén a asumir o reemprazo da tradición oral.

$\mathrm{Na}$ sociedade tendente á modernización, almanaque e calendario representarían elementos de manexo ou xestión da organización social e, como afirma Torres ${ }^{32}$, son obxectos sociais útiles para estruturar o marco temporal da vida pública e privada dos grupos humanos. Os calendarios constituirían elementos lexitimadores do sistema social, pois as estructuras de poder necesitan das lexitimacións explicativas da orde institucional que lles concedan validez. Tanto os calendarios coma outros instrumentos de medición temporal eríxinse como elementos relevantes para a orde social, porque teñen a utilidade de sincronizar os comportamentos, reforzar o sentido de grupo ao realizar actos en común e levan a que toda a sociedade encontre o seu sentido propio chamando segundo o seu costume a esas interrupcións, ás súas festas, a eses ciclos necesarios que se repiten. Cada sociedade manten así o seu propio tempo, a súa propia dinâmica. ${ }^{33}$

Aínda que a través do cambio para a palabra escrita, pretendeuse a modificación dos usos sociais en favor da modernización social nun espazo e tempo concretos, proceso do que formou parte a propia diversificación de contidos dos calendarios, que se foi producindo, creando unha tensión entre as permanencias e os cambios.

Tempo e escola. A funcionalidade dos calendarios como mediacións informais colaboradoras da obra de formación.

$\mathrm{Na}$ historia da educación é consabida a importancia da escola ao longo dos séculos XIX e XX na instrucción das clases populares e na extensión social dos chamados 'saberes

\footnotetext{
${ }^{28}$ Joaquín García Carrasco, "Educación informal de personas adultas en culturas orales lectoescritoras e informacionales", Revista de Educación. Monográfico de Educación no formal, ํo 338 (2005): 33.

${ }^{29} \mathrm{Ibid}$., 34-35.

${ }^{30} \mathrm{Ibid}$., 34-35.

${ }^{31}$ Louis-Jean Calvet, Historia de la escritura. De Mesopotamia hasta nuestros días (Barcelona: Paidós, 2001).

${ }^{32}$ Pablo Antonio Torres, Enseñanza del tiempo histórico. Historia, Kairós y Cronos. Una unidad didáctica para el aula de ESO (Madrid: Ediciones de la Torre, 2001), 33.

${ }^{33} \mathrm{Ibid} ., 43$.
} 
elementais'34, mediante a vía da educación formal. Del Pozo e Ramos ${ }^{35}$ observaron, a través da expresión escrita escolar, nunha mostra de cadernos escolares infantís datados entre 1922 e 1942, a importancia atribuida á instrucción, aos logros culturais, á adquisición de coñecementos, ao estudo e á formación intelectual como preparación para a vida futura. A mensaxe latente tras estas probas radicaba "na necesidade de acudir á escola para conseguir a formación necesaria, xa que autoeducación individual era imposible se non se dominaban os mecanismos da lectura e a escritura" ${ }^{36}$. Recomendábase a asistencia continuada á escola, que era considerada o lugar adecuado no que podían adquirirse os coñecementos, coa fin de mellorar as condicións sociais do educando.

Sendo así, o almanaque -obxecto da presente análise- carecería de intencionalidade educativa no ámbito formal. Mais, na esfera da investigación histórico-educativa non se pode descoñecer a incidencia do que se convén en chamar a educación informal ${ }^{37} ; \mathrm{e}$, neste senso, hai que salientar que os almanaques teñen obrado como un recurso de educación non intencional ao longo dun amplo contínuo histórico. E, por iso, o prólogo "A los lectores" no Almanaque popular y religioso de España para el año 1849 preséntase como un recurso válido para a consulta de case a totalidade do coñecemento útil. Podemos pensar que esta utilidade é posible facela extensible ao conxunto de almanaques da época:

El almanaque es el libro que se dirige especialmente a la familia y debe redactarse, por tanto, en términos que pueda ésta buscar en cada día la instrucción y la enseñanza prácticas (...). (...) debe ser el "vademécum" de cada uno de los miembros de la familia, cualquiera que sea su edad y su clase. Debe contener (...) los conocimientos indispensables a todos; tratando las cuestiones de moral, de educación, de derecho público, de agricultura, de horticultura, de higiene, de economía política, de comercio, de industria, de estadística, etc., de modo y forma que las personas de todos los sexos, edades y rangos encuentren alguna instrucción, alguna enseñanza útil y adecuada a sus gustos y profesiones. ${ }^{38}$

Neste caso, contemplaríase o almanaque como un recurso informal, susceptible de ser utilizado en determinadas aprendizaxes instrumentais como a lectura e a escritura e no achegamento aos varios rexistros lingüísticos, así como a unha ampla variedade de

\footnotetext{
${ }^{34}$ Jean Hébrard, "La escolarización de los saberes elementales en la época moderna", Revista de Educación, no 288 (1998): 63-104.

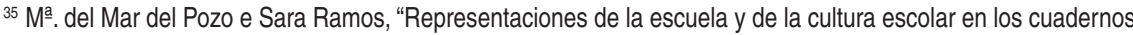
infantiles", en Mis primeros pasos. Alfabetización, escuela y usos cotidianos de la escritura (siglos XIX y XX), eds. Antonio Castillo e Verónica Sierra (Gijón: Trea, 2008), 213-242.

${ }^{36}$ Ibid., 214-215.

${ }^{37}$ En 1967, Philip H. Coombs, director do International Institute for Educational Planning, pertencente á UNESCO, populariza o termo de educación informal, no documento base The World Educational Crisis. A través desta expresión acuñada, afírmase que a oferta educativa é unha realidade independendente do sistema reglado de ensino. Aportación fundamental que sustenta e proporciona unha denominación ao proceso de oferta e adquisición de coñecementos na sociedade, producida e efectuada á marxe do sistema educativo oficial. A educación informal equivalería a un proceso extensivo ao conxunto dos anos de vida no que as persoas adquiren e acumulan coñecementos, habilidades ou actitudes; a educación non intencional formaría parte da mesma. Vid. Jaume Trilla et al, La educación fuera de la escuela. Ámbitos no formales y de educación social (Barcelona: Ariel, 2003), 18-19.

${ }^{38}$ Miryam Carreño, "Almanaques y calendarios...", 199.
} 
contidos relacionados con materias diversas, nunha especie de simbiose entre a "cultura escolar oficial" e a "cultura escolar popular", ás que se ten referido Narciso de Gabrieli3.

No caso dos almanaques editados en Galicia, os seus contidos inciden significativamente na reproducción da cultura popular, constituíndose así en instrumentos notables da socialización e de reprodución cultural, a través dun galego rico en infinitos dialectalismos e expresións coloquiais, que, na ausencia da consabida norma lingüística, reproduce a fala popular mais tamén a culta, vencellada neste caso máis específicamente ás aportacións literarias.

Os números consultados no Gaiteiro de Lugo dan conta daquelas informacións perentorias para as rutinas e a vida de cotío, así como tamén dunha serie de referencias culturais na esfera do contexto social ao que se dirixen. Os "contos" ou historias que se insertan son interpretadas por personaxes prototípicos do pobo, que protagonizan anécdotas das que acostuman saír ben parados a través do seu inxenio dialéctico. As situacións que se ilustran constitúen un fondo de estampas, xa verosímiles, xa caricaturescas, que mostran o entramado social tradicional galego.

Nas historias aparecen nenos, mozos e mozas, petrucios, homes e mulleres situados no campo e na aldea, na feira ou na capital, nunha misión relixiosa ou na escola; mais tamén aparecen gardas civís, médicos, criados, curas e sacristáns, soldados, mestres, estudantes sen cartos ou avogados, que dan conta da estratificación das ocupacións na sociedade tradicional. Ocasionalmente, os aconteceres políticos teñen o seu re exo entre as páxinas dos almanaques: por exemplo, no Gaiteiro de Lugo de 1928, os versos das páxinas iniciais anuncian a fin da guerra de Marrocos e o retorno dos soldados por orde de Primo de Rivera. A chegada da dictadura franquista deixará tamén a súa pegada en números posteriores do almanaque.

En relación á nomeada reproducción cultural, é de interese advertir que no transcurso do tempo apenas se observan as mínimas variacións na conformación da sociedade e nos valores culturais transmitidos polos almanaques, aínda que é posible suliñar, por exemplo, a referencia non exenta de crítica, no Gaiteiro de Lugo de 1929, da aparición dun novo modelo feminino nas clases altas, que o redactor introduce en Cousas dá moda, ao falar dunha señorita moi empingorotada d'esas que saben montar en bicicleta, guiar un automóvil, xugar o fútbol, fumar -y embadurnarse a cara -( ...) y-en troques non saben dar unha puntada, nin freir un ovo, nin criar un fillo, nin ( ...) ser amas d'unha casa ...

Non obstante, a publicación dos almanaques ao longo de décadas sucesivas apenas re icte as fondas transformacións socio-económicas acaecidas ao longo do século XX, cambios que introduciron modificacións na relación entre os estratos sociais, así como na lóxica das culturas tradicionais. No almanaque, a sociedade galega semella posuír unhas claves fixas e inmutables que se manteñen nas diferentes publicacións ao longo dos anos, mentres que son outros os elementos que dan conta dos evidentes cambios sociais, fundamentalmente a través das novidades anunciadas na publicidade. Por

${ }^{39}$ Narciso De Gabriel, "Clases populares y culturas escolares", 252-253. 
exemplo, en 1973 O Gaiteiro de Lugo inserta publicidade de Fontecelta, auga engarrafada de distribución industrial, "El agua con morriña", así como da Caja Rural Provincial de Lugo, "Al servicio exclusivo del campo lugués".

Estamos ante o emprego do almanaque como elemento de reprodución e vehículo para a cohesión social: un recurso que ilustra e re icte a sociedade na que é orixinado e da que son parte os seus potenciais lectores; válido tamén para a continuidade da construción cultural, nun sentido individual e colectivo.

Sen dúbida, ás necesidades da lectura arraigadas en experiencias individuais ou comunitarias están presentes ${ }^{40}$ mesmo en sociedades tradicionais máis alonxadas do que a nosa da cultura impresa: referírese, por exemplo, á utilización, desde o século XVI, de libros como guías para o traballo manual nas prácticas profesionais dos obradoiros. Neste sentido, estáse a falar da adquisición dunha instrución a partir da lectura de textos escritos fóra do contexto escolar.

É posible establecer un paralelismo entre o uso do material mencionado e a utilización do calendario como instrumento de formación colectiva dun pobo que participa do mesmo contexto cultural. Caro Baroja ${ }^{41}$ cita a Charles Nissard como estudioso da literatura de cordel ou da littérature du colportage francesa, para quen esta inclúe textos literarios xunto con "almanaques, pronósticos, epitomes de ciencias e artes elementalísimos e doutros tratadillos nos que abundou". Vendida por quincalleiros e vendedores ambulantes, para Caro Baroja ${ }^{42}$ a literatura de cordel correspondente aos séculos XVI, XVII, XVIII e XIX ofrece a idea máis perfecta dos procesos de formación estritamente populares, pois popular é o seu público.

O contexto cultural compartido favorece a produción da crenza sobre o valor do produto, que para Bourdieu é unha condición necesaria na creación do produto intelectual. O almanaque pode encontrarse, entón, formando parte desa sorte de documentos dos que fala Bourdieu, susceptibles de pasar ao estado da práctica, como escritos destinados a comunicar unha forma de facer ou de actuar, sen que precisen da mediación para 0 seu desciframento. Dalgún xeito, evitaríase o impacto negativo da cultura erudita sobre a cultura popular, a través do que o pobo ficaría perdido ou desposuído das súas formas de expresión cultural, xa deslexitimadas. Neste caso, a palabra impresa operaría, con algunha relevancia, como un espello da identidade colectiva, susceptible de obrar, nun amplo sentido, como recurso formativo, probablemente "mediante complexas formas de adopción, simbioses e sincretismos, como modo de apropiación da cultura letrada e de resignificación por parte dos sectores subalternos", tal como indicou Cucuzza ${ }^{43}$ no momento de referirse á lectura como práctica socio-histórica na liña adiantada por A. M. Chartier sobre as estratexias de apropiación da cultura letrada.

\footnotetext{
${ }^{40}$ Pierre Bourdieu, El sentido social del gusto, 259-260.

${ }^{41}$ Julio Caro Baroja, Ensayo sobre la literatura de cordel (Madrid: Itsmo, 1990), 63.

${ }^{42} \mathrm{Ibid} ., 64$

${ }^{43}$ Héctor Rubén Cucuzza (Dir.); Anne-Marie Spregelburd (Codir.), Historias de la lectura en la Argentina (Buenos Aires: Editoras del Calderón), 14.
} 